\title{
Negligible influence of livestock contaminants and sampling system on ammonia measurements with cavity ring-down spectroscopy
}

\author{
Jesper Nørlem Kamp ${ }^{1,2}$, Albarune Chowdhury ${ }^{1}$, Anders Peter S. Adamsen ${ }^{1, a}$, and Anders Feilberg ${ }^{1}$ \\ ${ }^{1}$ Department of Engineering, Aarhus University, 8000 Aarhus, Denmark \\ ${ }^{2}$ Arctic Research Centre, Aarhus University, 8000 Aarhus, Denmark \\ ${ }^{a}$ now at: APSA, 8800 Viborg, Denmark
}

Correspondence: Anders Feilberg (af@eng.au.dk)

Received: 25 October 2018 - Discussion started: 29 November 2018

Revised: 12 April 2019 - Accepted: 1 May 2019 - Published: 17 May 2019

\begin{abstract}
Emission of ammonia $\left(\mathrm{NH}_{3}\right)$ is a ubiquitous problem due to the adverse effects of $\mathrm{NH}_{3}$ on the environment and human health. The agricultural sector accounts for nearly all $\mathrm{NH}_{3}$ emissions in Europe. Hence, technologies for the abatement of $\mathrm{NH}_{3}$ emissions from this sector have been in strong demand in recent years. In order to document emissions and evaluate abatement technologies, there is a strong need for reliable $\mathrm{NH}_{3}$ measurement methods. Photoacoustic spectroscopy (PAS) is often used to measure $\mathrm{NH}_{3}$ concentrations, but recent research shows interference from compounds typically present in livestock production and during agricultural activities. In this work, the performance of cavity ring-down spectroscopy (CRDS) from Picarro, as an alternative to PAS, has been tested with respect to method validation under laboratory and field conditions. Potential interferences of 10 volatile organic compounds (VOCs) on CRDS $\mathrm{NH}_{3}$ measurement were tested with simultaneous VOC analysis performed by proton-transfer-reaction mass spectrometry (PTR-MS). Both laboratory and field calibrations show excellent linearity over a large dynamic range of $\mathrm{NH}_{3}$ concentrations. The analyzer shows a small humidity effect of up to a few ppb in the extreme case of a nearly water-saturated air stream. Apart from the negligible humidity dependency, no interferences of the tested VOCs were observed. Overall, the CRDS system performs satisfactory and is well suited for measurements of $\mathrm{NH}_{3}$ emissions from livestock production.
\end{abstract}

\section{Introduction}

Ammonia $\left(\mathrm{NH}_{3}\right)$ is an important atmospheric pollutant with several adverse effects: deposition of $\mathrm{NH}_{3}$ can lead to eutrophication and acidification, which has negative effects on biodiversity (Sheppard et al., 2011). $\mathrm{NH}_{3}$ is a precursor of atmospheric aerosols thereby influencing the global radiation budget as well as having a negative influence on human health (Aneja et al., 2001; Baek et al., 2004). In addition, microbial oxidation of $\mathrm{NH}_{3}$ results in secondary production of nitrous oxide $\left(\mathrm{N}_{2} \mathrm{O}\right)$ and nitric oxide (NO) (Zhu et al., 2013). $\mathrm{N}_{2} \mathrm{O}$ is a very potent greenhouse gas (GHG) and NO is involved in atmospheric reactions producing tropospheric ozone (Aneja et al., 2001).

Agricultural activities, mainly manure application and management, account for around $94 \%$ of $\mathrm{NH}_{3}$ emissions in Europe (Nielsen et al., 2017). Reliable measurements in the agricultural sector are highly important to give accurate estimates of $\mathrm{NH}_{3}$ emissions in order to reduce emissions, for example, by validation of technological improvements within the agricultural sector.

The ventilation air from animal production facilities contains a variety of chemical compounds, relatively high water content and high densities of particulate matter. This includes a great number of volatile organic compounds (VOCs) that are emitted in agricultural buildings from, e.g., silage, manure and the animals themselves (Feilberg et al., 2010; Hafner et al., 2013; Hansen et al., 2012; Ngwabie et al., 2008; Shaw et al., 2007; Yuan et al., 2017). Several $\mathrm{NH}_{3}$ analyzers are sensitive to water vapor and other gasses (Bobrutzki et al., 2010; Huszár et al., 2008; Ni and Heber, 2008; Rom and Zhang, 2010; Rosenstock et al., 2013). Such interferences 


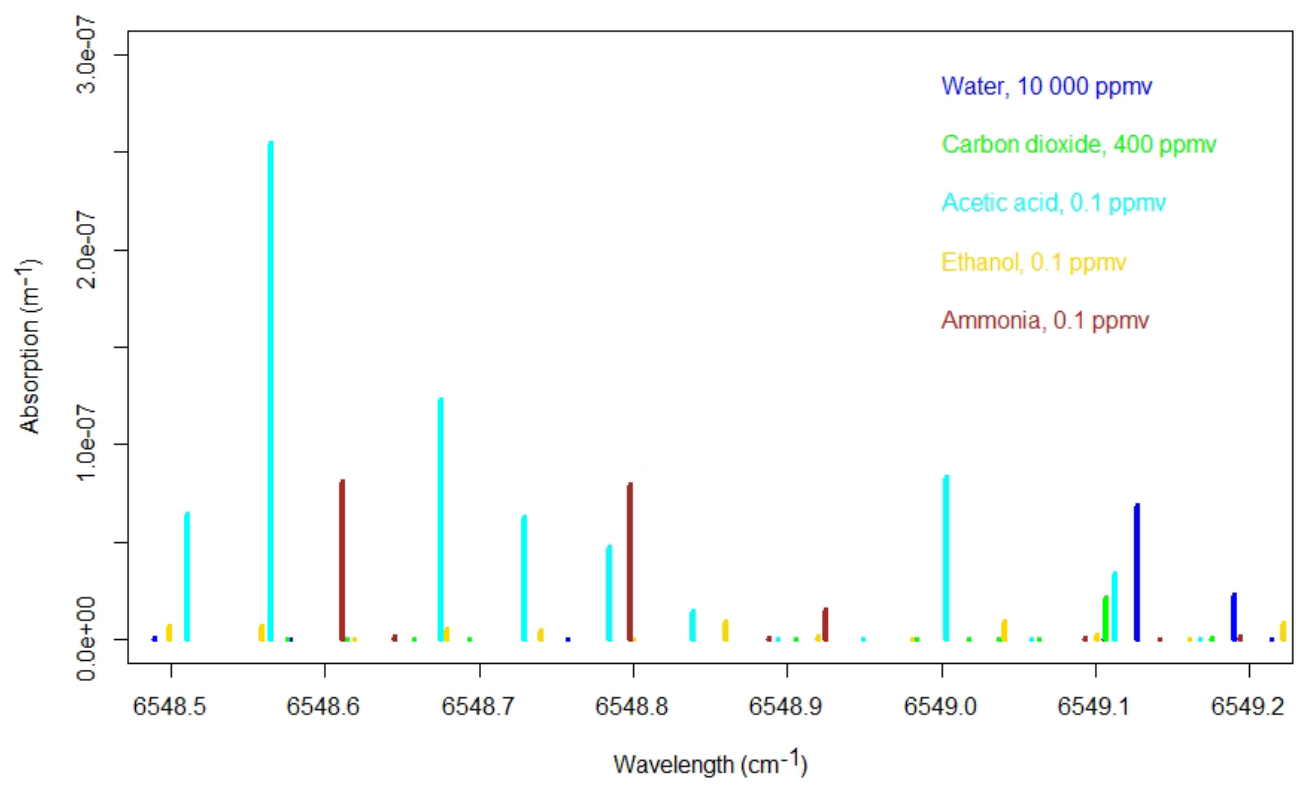

Figure 1. Simulated absorption spectrum from the HITRAN database for $1 \% \mathrm{H}_{2} \mathrm{O}$ (blue), $400 \mathrm{ppm} \mathrm{CO}_{2}$ (green), $100 \mathrm{ppb}$ acetic acid, $100 \mathrm{ppb}$ ethanol, and $100 \mathrm{ppb} \mathrm{NH}_{3}$ at $45^{\circ} \mathrm{C}$ and 187 mbar.

can introduce errors depending on the instrument used. Furthermore, it is challenging to measure $\mathrm{NH}_{3}$ concentrations correctly due to its high water solubility and polarity, which causes adsorption on surfaces in the sampling system and within the instrument (Rom and Zhang, 2010; Shah et al., 2006; Vaittinen et al., 2014). This "sticky nature" of $\mathrm{NH}_{3}$ causes delays in the measurements, giving longer response times (Rom and Zhang, 2010; Shah et al., 2006; Vaittinen et al., 2014). It is an additional challenge to measure $\mathrm{NH}_{3}$ in livestock buildings, where dust and particles provide large surface areas for adsorption in particulate filters used to protect measuring instruments.

In many agricultural emission studies, photoacoustic spectroscopy (PAS) (Poissant et al., 2005; Rom and Zhang, 2010; Saha et al., 2010; Wu et al., 2012; Zhang et al., 2005; Zong et al., 2014) has been used, but findings by Rosenstock et al. (2013) and Liu et al. (2019) show high interference on $\mathrm{NH}_{3}$ measurements from a variety of organic compounds including carboxylic acids and alcohols. Hassouna et al. (2013) reported nonconstant bias in the results from PAS measurements on $\mathrm{NH}_{3}$ and $\mathrm{N}_{2} \mathrm{O}$ caused by organic compounds often present at agricultural sites, which makes the PAS measurements unreliable in an agricultural setting. Another issue with PAS measurements is the long response time of up to 25 min (Rom and Zhang, 2010), which lowers the time resolution of emission measurements under dynamic conditions. $\mathrm{NH}_{3}$ is underestimated by approximately $14 \%$ and $2 \%$ after 12.5 and $25 \mathrm{~min}$, respectively (Rom and Zhang, 2010). Typical measurements in cattle barns take place at multiple points. For example, Rong et al. (2014) measured at 7 points in a dairy cow building and Ngwabie et al. (2009) measured at 11 points in a dairy cow barn. The cycle time for a typical setup in a barn would therefore be on the order of $3-5 \mathrm{~h}$, which makes it impossible to monitor temporal variations with only 4-8 measurements per measurement point per day. Thus, the response time is a key parameter for equipment measuring at multiple points as done in livestock buildings.

In a few recent studies, cavity ring-down spectroscopy (CRDS) has been used to measure ammonia concentrations (Maasikmets et al., 2015; Sintermann et al., 2011) in agricultural settings. The CRDS provides measurements in real time with high sensitivity, high selectivity and a fast response time. The CRDS analyzer maintains high linearity, precision and accuracy over changing environmental conditions without the need for frequent calibration. The work of Martin et al. (2016) led to an improvement of water vapor interference calculations on Picarro's CRDS for $\mathrm{NH}_{3}$ measurements. The scaling factor error they discovered is approximately $2 \%$ of the absolute water concentration.

Bobrutzki et al. (2010) conducted a field intercomparison of 11 atmospheric $\mathrm{NH}_{3}$ measurement techniques at concentrations up to $120 \mathrm{ppb}$ including cavity ring-down spectroscopy (CRDS), and the results show a good overall agreement between the instruments on an hourly basis $\left(R^{2}>0.84\right)$.

Our aim is to demonstrate the performance of the CRDS analyzer for measurements of $\mathrm{NH}_{3}$ gas concentration under laboratory and field conditions. This includes identification and quantification of potential interferences by compounds present in livestock buildings by using protontransfer-reaction mass spectrometry (PTR-MS) to document VOC concentrations in laboratory tests. 

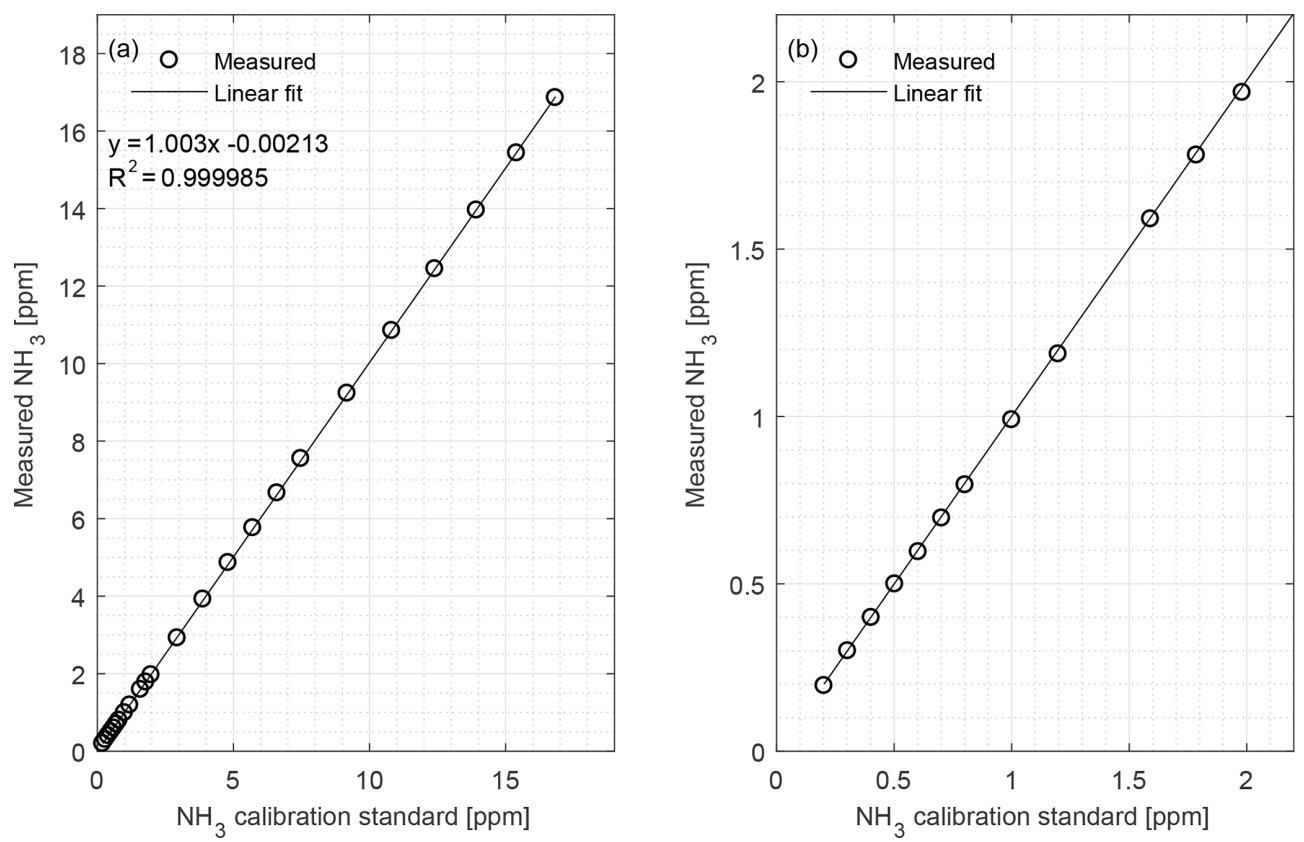

Figure 2. (a) Calibration curve of the CRDS from 0.20 to $16.8 \mathrm{ppm} \mathrm{NH}_{3}$ conducted under laboratory conditions; (b) calibration curve limited to 0 to $2 \mathrm{ppm}$. Symbols represent measured values, error bars the standard deviation and the line is the fitted regression model.

Due to the major concerns regarding measurements of $\mathrm{NH}_{3}$ with PAS (Hassouna et al., 2013; Liu et al., 2019; Zhao et al., 2012), it is pertinent that any influence of VOC on CRDS is thoroughly documented, which to our knowledge has not been done previously. The absorptions lines of, for example, acetic acid and methanol found in the HITRAN database (Gordon et al., 2017) are in the same range as the ammonia lines used for measurements in the CRDS; see Fig. 1. This highlights the importance of the current study as the absorption by VOCs in principle may cause similar interference, as reported by Rosenstock et al. (2013) and Liu et al. (2019) for PAS.

This study aims to validate CRDS for measurements in the agricultural industry, thus we test for interference with a number of compounds typically present in pig houses and cattle farms for which $\mathrm{NH}_{3}$ concentration and emission measurements are routinely carried out. Laboratory tests include determination of the response parameters linearity, response time, influence of particulate filters and chemical interference. Field tests include determination of the response parameters linearity, response time and particulate filter effect.

\section{Materials and methods}

\subsection{Chemicals, reagents and gasses}

We used the following chemicals during the experiments: $70 \mathrm{mM}$ acetic acid (VWR int. S.A.S., Fontenaysous-Bois, France), $27 \mathrm{mM}$ 1-propanol (Merck KGaA, Darmstadt, Germany), $1.3 \mathrm{mM}$ 2-propanol (Sigma-Aldrich
Chemie GmbH, Steinheim, Germany), $0.7 \mathrm{mM}$ acetaldehyde (Sigma-Aldrich), $4 \mathrm{mM}$ propionic acid (Alfa Aesar $\mathrm{GmbH} \&$ Co KG, Karlsruhe, Germany), $0.8 \mathrm{mM}$ acetone (Merck), $10 \mathrm{mM}$ methanol (VWR), $2.2 \mathrm{mM}$ 1-butanol (Merck), $69 \mathrm{mM}$ ethanol (CCS Healthcare AB, Borlänge, Sweden) and $44 \mathrm{mM}$ butanoic acid (Alfa Aesar). Deionized water dissolved the chemicals to the desired concentrations.

We used the following gasses during the experiments: $101 \mathrm{ppm} \mathrm{NH} \mathrm{NH}_{3}( \pm 10 \%)$ in $\mathrm{N}_{2} \mathrm{O}$ calibration gas (AGA A/S, Copenhagen, Denmark), pure (99.99\%) $\mathrm{CO}_{2}$ (AGA), pure (99.99\%) $\mathrm{CH}_{4}$ (AGA), and as compressed zero air passed through a bed of silica gel and charcoal to remove water, ozone, hydrocarbons and other common contaminants. Mass flow controllers (MFCs) from the EL-FLOW (Bronkhorst High-Tech B.V., Ruurlo, Netherlands) series regulated all gas flows with an accuracy of $\pm 5 \%$.

\subsection{Instrumentation}

The operational principle of CRDS relies on ring down time laser light. An air sample enters a cavity at low pressure $(18.665 \mathrm{kPa}, 140$ Torr) and laser light is pulsed into the cavity, where almost all light is reflected by mirrors, which gives an effective path length of kilometers. A small fraction of the light penetrates the mirrors to reach the detector and the intensity of the light is proportional to the concentration of target gas, as the target gas will absorb light. The G2103 analyzer measures absorption from 6548.5 to $6549.2 \mathrm{~cm}^{-1}$ (Martin et al., 2016), and Fig. 1 shows the absorption of some selected compounds in this range obtained from the HITRAN 

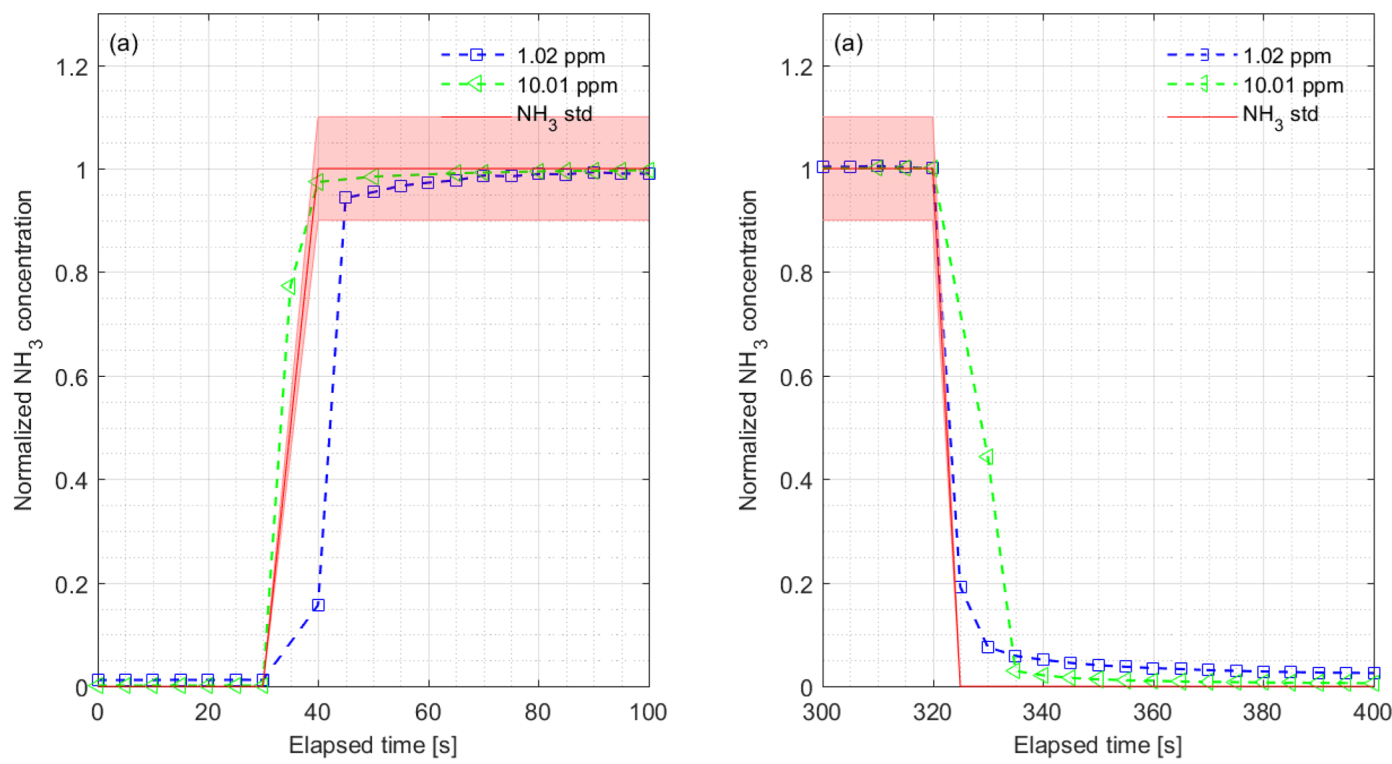

Figure 3. (a) Rise time and (b) fall time for the CRDS measurements normalized to final concentrations during laboratory testing of the response to a step change to 1.02 (blue) and $10.01 \mathrm{ppm}$ (green). The results show $\mathrm{NH}_{3}$ to $1.02 \mathrm{ppm}$ with rise time $(1 / e)=8.1 \mathrm{~s}$ and fall time

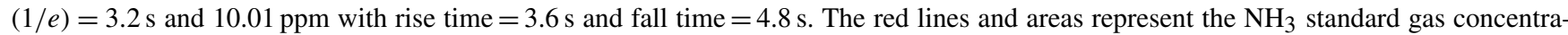
tion with $10 \%$ accuracy, the blue markers show the normalized concentration from $1.02 \mathrm{ppm}$ and the green markers show the normalized concentration from $10.01 \mathrm{ppm}$.
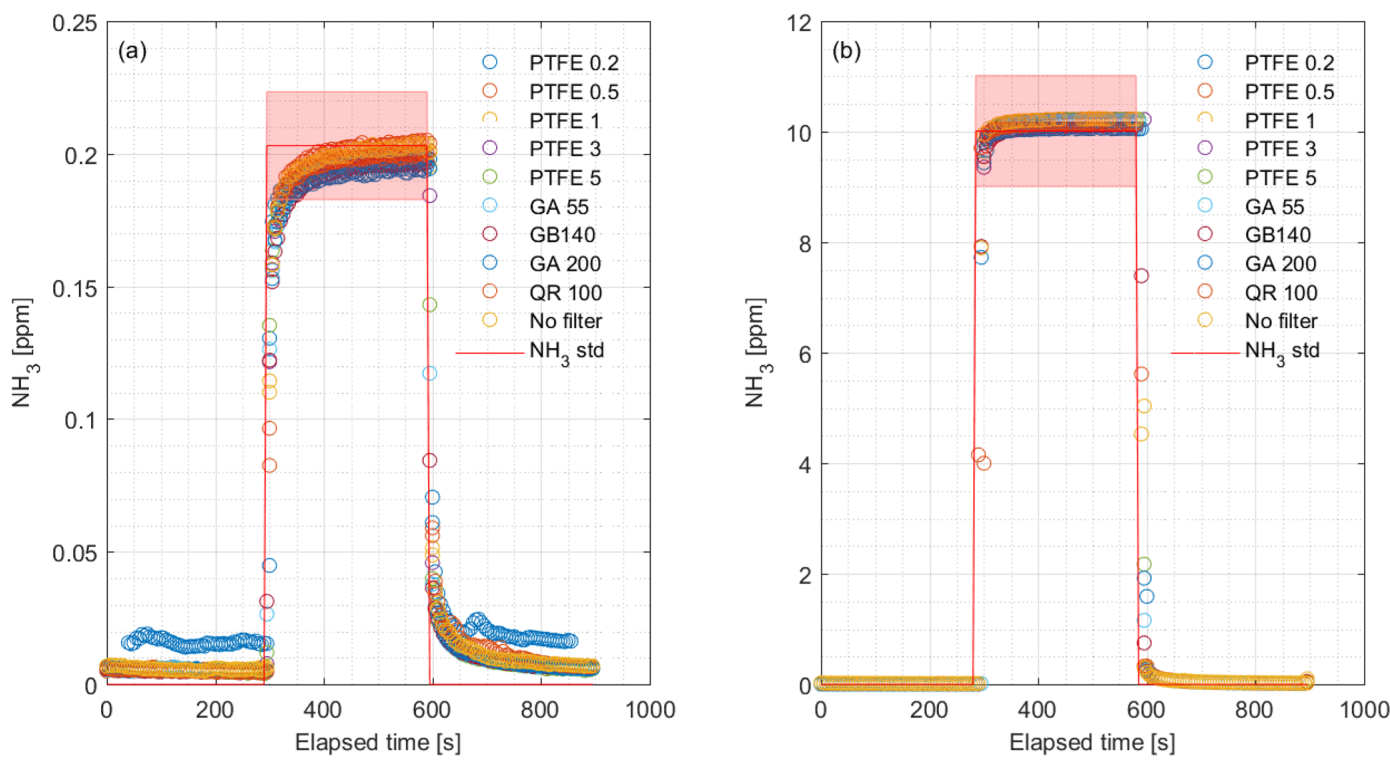

Figure 4. The response to a step change in $\mathrm{NH}_{3}$ at (a) 0.203 and (b) $10.01 \mathrm{ppm}$ with and without external inlet filters during laboratory testing. The red line and area represent the $\mathrm{NH}_{3}$ standard gas concentration with $10 \%$ accuracy. See the legend abbreviations in Table 1 .

2016 database (Gordon et al., 2017). The computed absorption lines in Fig. 1 correspond to $1 \% \mathrm{H}_{2} \mathrm{O}, 400 \mathrm{ppm} \mathrm{CO}_{2}$, $100 \mathrm{ppb}$ acetic acid, $100 \mathrm{ppb}$ ethanol and $100 \mathrm{ppb}$ ammonia at $45^{\circ} \mathrm{C}$ and 140 Torr. Line broadening is not taken into account.

For the determination of interference, we used a Picarro $\mathrm{NH}_{3} / \mathrm{H}_{2} \mathrm{O}$ analyzer model G2103 (Picarro Inc., Santa Clara,
CA, USA) to measure the $\mathrm{NH}_{3}$ concentration continuously, this CRDS analyzer has not incorporated the upgraded water correction. A high-sensitivity PTR-MS (Ionicon Analytik, Innsbruck, Austria) measured concentrations of different VOCs for the interference tests. The drift tube setting was $600 \mathrm{~V}, 2.1-2.2 \mathrm{mbar}$ and $60^{\circ} \mathrm{C}$, which yield an $\mathrm{E} / \mathrm{N}$ of approximately $130 \mathrm{Td}$. Fragmentation of alcohols is normal 
Table 1. Specifications of tested particulate filters with abbreviations.

\begin{tabular}{lrrrrl}
\hline Filter material & Pore size $(\mu \mathrm{m})$ & Thickness $(\mathrm{mm})$ & Diameter $(\mathrm{mm})$ & Porosity $(\%)$ & Filter code \\
\hline PTFE* $^{*}$ & 0.2 & 0.08 & 25 & 74 & PTFE 0.2 \\
PTFE* & 0.5 & 0.08 & 25 & 78 & PTFE 0.5 \\
PTFE* & 1.0 & 0.08 & 25 & 79 & PTFE 1.0 \\
PTFE* & 3.0 & 0.08 & 25 & 83 & PTFE 3.0 \\
PTFE* & 5.0 & 0.08 & 25 & - & PTFE 5.0 \\
Glass fiber & 0.6 & 0.21 & 25 & - & GA 55 \\
Glass fiber & 0.4 & 0.56 & 25 & - & GB 140 \\
Glass fiber & 0.8 & 0.74 & 25 & - & GA 200 \\
Quartz fiber & - & 0.38 & 25 & - & QR 100 \\
\hline
\end{tabular}

* Polytetrafluoroethylene.

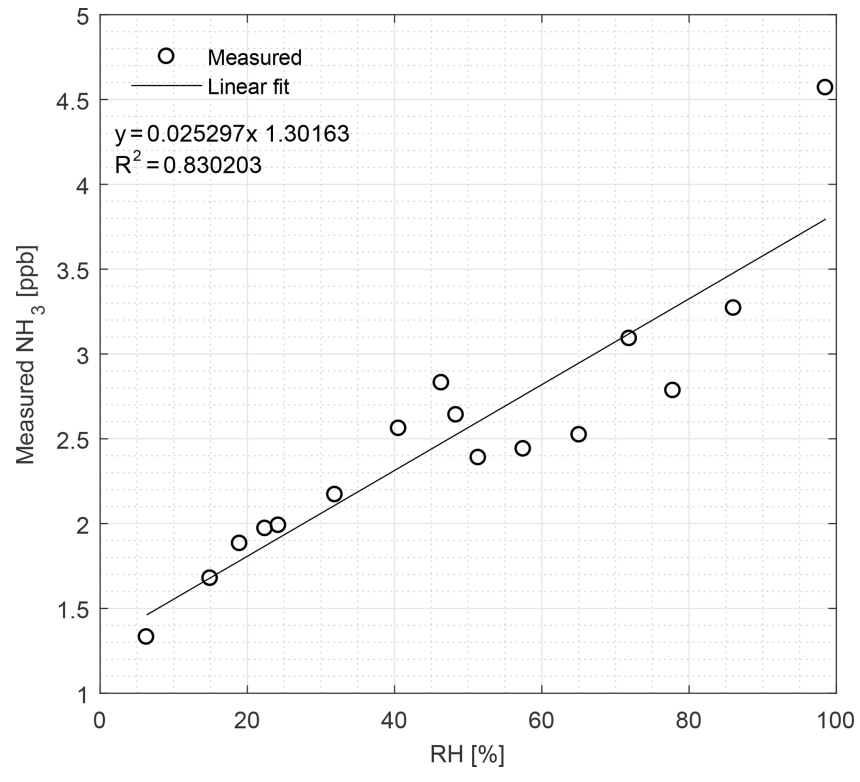

Figure 5. The CRDS signals of $\mathrm{NH}_{3}(\mathrm{ppb})$ in zero air at different concentrations of water vapor, ranging from $6 \%$ to $99 \%$ relative humidity $(\mathrm{RH})$ at $22{ }^{\circ} \mathrm{C}$ under laboratory conditions. Symbols represent measured values and the line is the fitted linear regression model.

in PTR-MS and we use the fragmentation of alcohols as described by Brown et al. (2010) to calculate the final concentration with all fragments taken into consideration.

One stream of clean air passed through the headspace air over an aqueous solution containing a single compound. Another stream diluted the outflow from the headspace. We changed the airflows to get different concentrations of the compound in the gas phase. The CRDS and PTR-MS received the diluted air streams.

\subsection{Linearity, calibration and filter effect}

We used a flow dilution system with zero air and $\mathrm{NH}_{3}$ calibration gas $(101 \mathrm{ppm})$ to test the linearity of the CRDS measurements. $\mathrm{NH}_{3}$ gas concentrations for the calibration were in the range from 0.20 to $16.8 \mathrm{ppm}$ in the laboratory and from 0.27 to $20.0 \mathrm{ppm}$ under field conditions. We performed the calibrations in the laboratory without external filters. Introduction of all gasses in the field was through a multiposition rotary valve (MPV, Cheminert low-pressure valve, model C25, VICI AG International, Schenkon, Switzerland) for $6 \mathrm{~min}$ while the CRDS was in normal sampling mode. We performed a single point calibration in the field to test the system integrity and analyzer response time by introducing $7.8 \mathrm{ppm} \mathrm{NH} \mathrm{NH}_{3}$ calibration gas directly into the sampling lines that were manually removed from their position. The response time for all experiments was found by fitting an exponential function to the step changes, which gave the efolding time. We tested the PTFE filters in the laboratory for $\mathrm{NH}_{3}$ signals by connecting filters used for 2 weeks to a clean air supply under heating to maximum $75^{\circ} \mathrm{C}$. Monitoring of the $\mathrm{NH}_{3}$ signals continued until the concentration went below $5 \mathrm{ppb}$; see Table 1 for abbreviations and specifications of the used filters.

We performed laboratory tests on the response time by switching between ambient air and $1.02 \mathrm{ppm} \mathrm{NH}_{3}$ with the MPV without external filters attached. We also tested response time to a step change in $\mathrm{NH}_{3}$ concentration with different external particulate filters attached. The concentrations were 0.203 and $10.01 \mathrm{ppm} \mathrm{NH}_{3}$ with filters of different pore sizes made of PTFE, glass fiber and quartz. Table 1 shows the specifications of the filters.

\subsection{Field testing}

We conducted field tests in a cattle barn with natural ventilation located in central Jutland outside Viborg, Denmark. The cattle barn is $9 \mathrm{~m}$ high, $60 \mathrm{~m}$ long and $36 \mathrm{~m}$ wide and naturally ventilated. We measured $\mathrm{NH}_{3}$ concentrations in the cattle building with the CRDS combined with a 10 port (P1- 

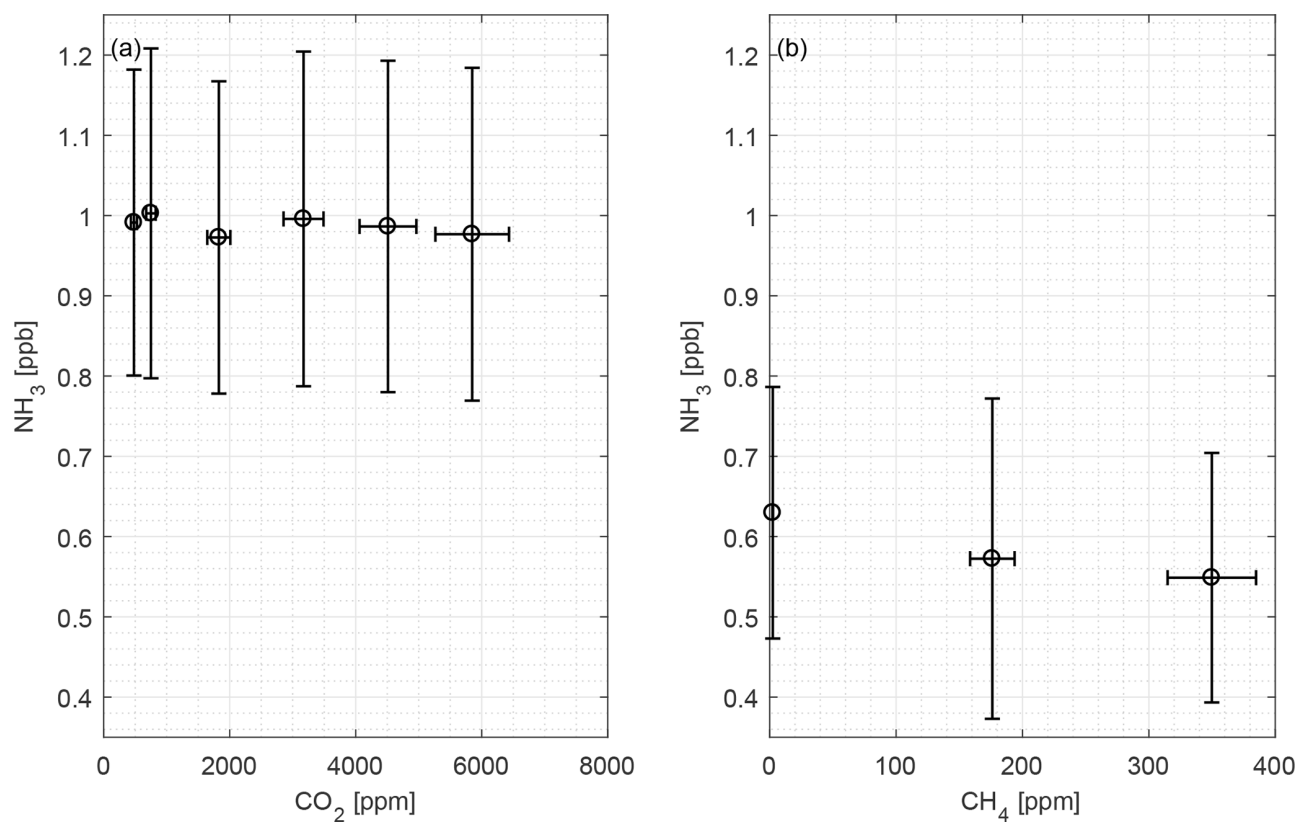

Figure 6. The CRDS signals of $\mathrm{NH}_{3}$ in zero air response to various concentrations of (a) $\mathrm{CO}_{2}(480-5848 \mathrm{ppm})$ and (b) $\mathrm{CH}_{4}$ (2.42-350 ppm) under laboratory conditions. Symbols represent measured values and vertical and horizontal bars the standard deviation of the measurements.

P10) MPV (C25-61800, VICI Valco Inst. Co. Inc., Texas, USA). Measurements were set up according to Rong et al. (2014) and $\mathrm{Wu}$ et al. (2012). We considered the division into three $20 \mathrm{~m}$ sections inside the cattle barn to be representative of the animal-occupied zone of the barn. We sampled $\mathrm{NH}_{3}$ concentrations from the three sections using PTFE tubes (inner diameter $6 \mathrm{~mm}, 20 \mathrm{~m}$ long) with 20 uniformly distributed sampling openings. The sampling points (SP) SP2, SP3 and SP4 were inside the building, with SP2 and SP4 on each of the end walls adjacent to the windows, i.e., sidewall openings, placed $2.5 \mathrm{~m}$ above the floor. SP3 was just below the ridge opening in the middle of the building, placed $9 \mathrm{~m}$ above the floor. SP1 and SP5 were outside background measurements from two single points placed $5 \mathrm{~m}$ from the building sidewalls at $2.5 \mathrm{~m}$ height. The sample tubes were between 5 and $50 \mathrm{~m}$ long with heating cables attached to avoid condensation inside the tubing. The length of the sampling lines was approximately 5, 15, 35, 45 and $50 \mathrm{~m}$ for SP1, SP2, SP3, SP4 and SP5, respectively. See Fig. A1 in the Appendix. Each sampling line had a secondary suction pump (flow rate of 6-7 $\mathrm{L} \mathrm{min}^{-1}$ ) with a PTFE membrane to generate a constant flow through the lines. A PTFE filter $(0.20 \mu \mathrm{m}$ pore size) removed airborne particulate matter from the sample air before the sampling ports of the MPV. Replacement of filters was done at least fortnightly. Measurement lasted 6 min for each sampling port with automatic switching; i.e., a measurement cycle was $30 \mathrm{~min}$.

We used pure deionized water to produce a range of different humidity levels. Figure 5 shows the effects of the humidity on the $\mathrm{NH}_{3}$ signal from relative humidity $(\mathrm{RH})$ ranging
Table 2. Limit of detection and limit of quantification from a $1 \mathrm{~h}$ stable measurements on zero air.

\begin{tabular}{lrrrrr}
\hline & $\mathrm{N}$ & Mean & $\mathrm{SD}$ & LOD $(3 \times \mathrm{SD})$ & LOQ $(10 \times \mathrm{SD})$ \\
\hline $\mathrm{H}_{2} \mathrm{O}[\%]$ & 2065 & 0.082 & 0.0019 & 0.006 & 0.019 \\
$\mathrm{NH}_{3}[\mathrm{ppb}]$ & 2065 & 0.636 & 0.115 & 0.345 & 1.151 \\
\hline
\end{tabular}

from $6.3 \%$ to $98.6 \%$. The response to the change in humidity is linear $\left(R^{2}=0.83\right)$ with $\mathrm{NH}_{3}$ measurements from 1.3 to $4.6 \mathrm{ppb}$ over the given $\mathrm{RH}$ range.

\section{Results}

\subsection{Laboratory tests}

The CRDS had a highly linear response $\left(R^{2}=0.99998\right)$ to $\mathrm{NH}_{3}$ concentrations over the dynamic range $0.20-16.8 \mathrm{ppm}$ (Fig. 2). This range is chosen from the expected concentration in a livestock facility as seen in Figs. A2 and A3, which show the hourly mean concentration of $\mathrm{NH}_{3}$ in four rooms with finisher pigs and a dairy cattle barn, respectively. The maximum concentration can exceed $15 \mathrm{ppm}$ in the pig houses and $3 \mathrm{ppm}$ in the cattle barn. The $\mathrm{NH}_{3}$ standard calibration gas used for all calibrations had an accuracy of $\pm 10 \%$ stated by the manufacturer. The measured $\mathrm{NH}_{3}$ concentrations in Fig. 2 are averages of several hundred measurements and the standard deviations are indicators of stability. Figure $3 a$ and $b$ shows the result of a step change in concentration from clean air to 1.02 and $10.01 \mathrm{ppm}$, respectively, and back to clean air. The rise time to the final concentration level minus $1 / e$ was 

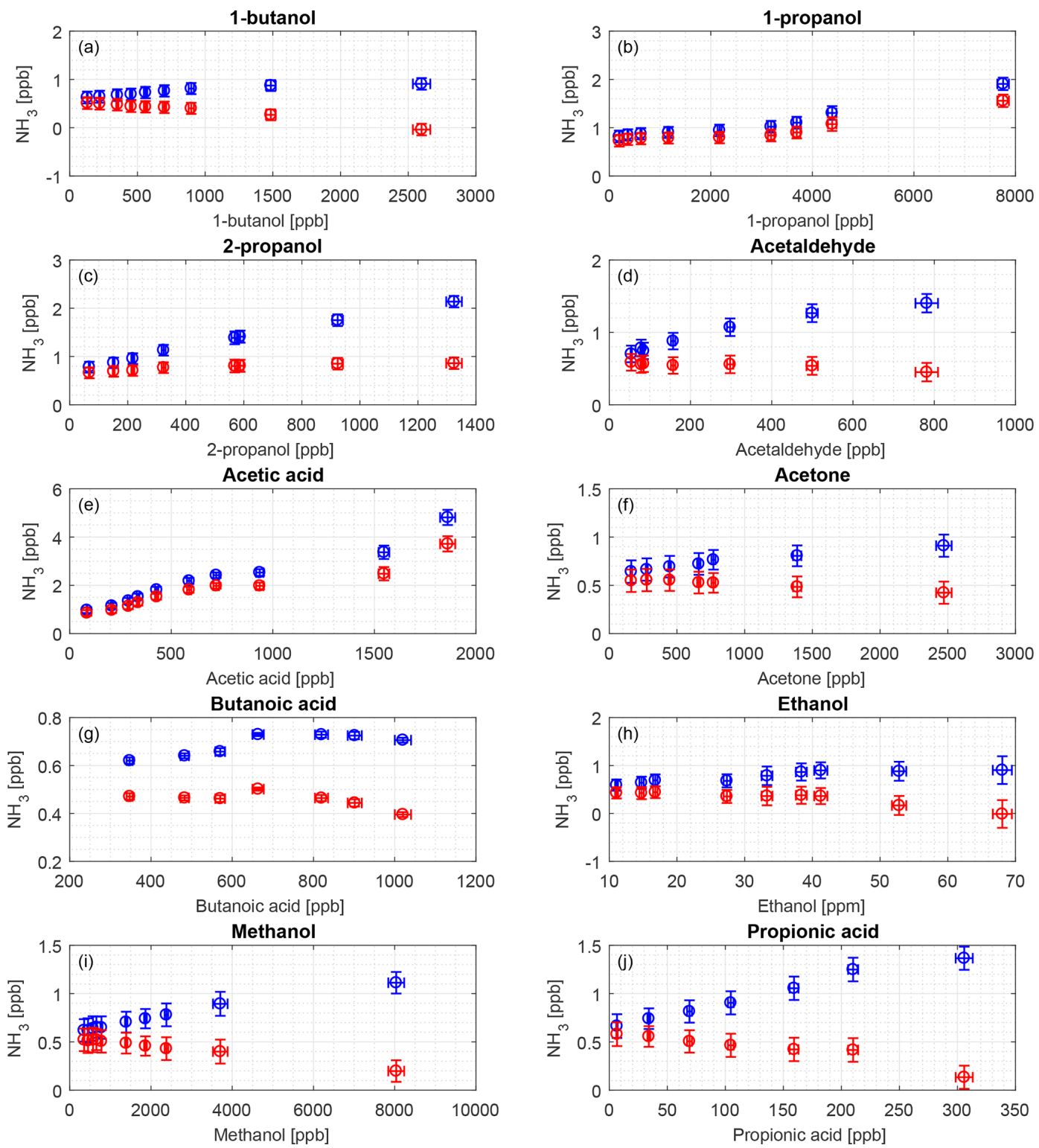

Figure 7. Interference of different organic compounds on the $\mathrm{CRDS} \mathrm{NH}_{3}$ measurement. Blue markers indicate the original data and red markers indicate water-corrected data from the regression shown in Fig. 5. The compounds are (a) 1-butanol, (b) 1-propanol, (c) 2-propanol, (d) acetaldehyde, (e) acetic acid, (f) acetone, (g) butanoic acid, (h) ethanol, (i) methanol, and (j) propionic acid.

8.1 and $3.6 \mathrm{~s}$ and the fall time to $1 / e$ of the final concentration level was 3.2 and $4.8 \mathrm{~s}$ for 1.02 and $10 \mathrm{ppm}$, respectively. Furthermore, Fig. 4 shows response times to step changes to two concentrations ( 0.203 and $10.01 \mathrm{ppm})$ with different types of external particulate filters. The response times varied for the different filter types, with an average rise and fall time of 8.1 and $6.3 \mathrm{~s}$ (for $0.203 \mathrm{ppm}$ ) and 3.1 and $3.7 \mathrm{~s}$ (for $10.01 \mathrm{ppm}$ ), respectively (Fig. 4). Across all filter types, the response time was fastest for changes to the highest concentration except the fall time for three filters; see details in Table A2.

Measurements on zero air over an hour gave a standard deviation on the $\mathrm{NH}_{3}$ concentration of $0.115 \mathrm{ppb}$. This gives a limit of detection (LOD) of $0.35 \mathrm{ppb}$ for three standard deviations and a limit of quantification (LOQ) of $1.15 \mathrm{ppb}$ for 10 standard deviations; see Table 2.

Figure 6 shows the CRDS signals from $\mathrm{CO}_{2}$ and $\mathrm{CH}_{4}$ with random fluctuations in the low ppb level being observed. There are no apparent interferences from these two compounds. All measured $\mathrm{NH}_{3}$ concentrations for both compounds are below the LOQ.

Figure 7 shows the interferences of 10 different VOCs with VOC concentration as a function of $\mathrm{NH}_{3}$ concentration corrected for water contribution and the uncorrected concentration as well. This correction was due to a clear pattern 


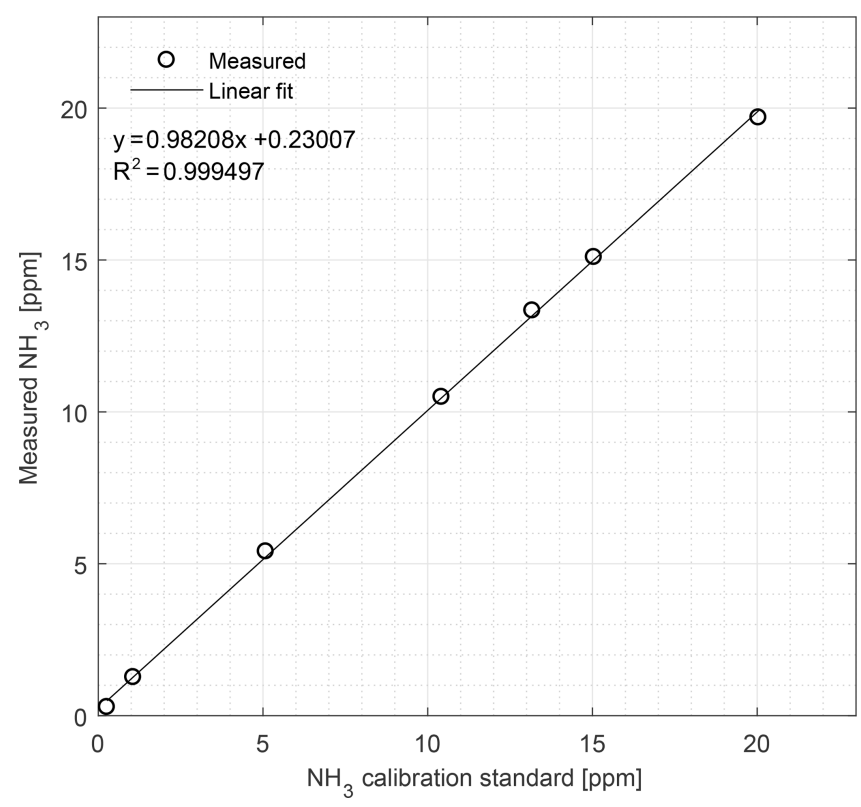

Figure 8. Calibration curve of the CRDS from 0.27 to $20.04 \mathrm{ppm}$ $\mathrm{NH}_{3}$ conducted under field conditions. Symbols represent measured values and the line is the fitted linear regression model.

for increased water vapor with VOC concentration as water is introduced with the VOCs, and $\mathrm{NH}_{3}$ concentration increased with increased water vapor for all compounds. The observed interferences were in the range from 0.5 to $5 \mathrm{ppb}$ $\mathrm{NH}_{3}$ equivalents at VOC concentrations from 6 to $8000 \mathrm{ppb}$. These VOC concentrations range from levels comparable to field conditions up to levels 1-2 orders of magnitude higher than maximum field conditions.

\subsection{Field tests}

In the field, the CRDS also has a highly linear response $\left(R^{2}=0.9995\right)$ in the concentration range $0.27-20.04 \mathrm{ppm}$; see Fig. 8. Figure 9 shows the results of a single point field calibration of the system integrity and response time to a sudden change to $7.8 \mathrm{ppm}$ with response times varying from 6 to $25 \mathrm{~s}$. The calibration gas used in the measurements shown in Figs. 8 and 9 had an uncertainty of $\pm 10 \%$.

Figure 10 shows the ammonia concentrations released from external particulate filters that have been exposed to ammonia in a livestock house for 2 weeks. Vacuum pumps applied a gas flow rate of minimum $6 \mathrm{~L} \mathrm{~min}^{-1}$ through the filter over the 2 -week period, thus a minimum volume of $120 \mathrm{~m}^{3}$ of air went through each filter. The preexposed filters were flushed with zero air and ammonia release was monitored by CRDS. The concentration maximum varied between 25 and $38 \mathrm{ppb}$. The peak values are comparable to typical ambient laboratory concentrations ranging from 14 to $37 \mathrm{ppb}$; see Table A1.

\section{Discussion}

The CRDS analyzer had a linear response during both laboratory tests and field validation (Figs. 2 and 8 ) in the range from approximately 0.2 to $20 \mathrm{ppm} ; \mathrm{NH}_{3}$ concentrations in livestock buildings are normally within this range (Heber et al., 2006; Koerkamp et al., 1998) as seen in Figs. A1 and A2. This is in agreement with the manufacturer specifications that guarantee the range from 0 to $500 \mathrm{ppb}$ and an operational and optional expanded range up to 10 and $50 \mathrm{ppm}$, respectively (Picarro, 2017). The field calibrations show excellent agreement with the standard gas concentrations. The standard gas had an uncertainty of $\pm 10 \%$, according to the data sheet from the manufacturer. This may well explain the small offset $(<4 \%)$ from the obtained concentrations seen in Fig. 9, but the system causes minor variations, as the bias is considered constant. The LOD $(0.35 \mathrm{ppb})$ found in the present study is comparable to the manufacturer's specifications for $1 \mathrm{~s}$ integration time, as seen in Table 2 . The performance of a single point field calibration showed very good agreement with the expected concentrations, as seen in Fig. 9. The potential bias from the zero air might also influence the other laboratory experiments, which can explain some of the variations we see in, for example, filter response (Fig. 4) or water dependency (Fig. 5).

It is a requirement to have fast responding analyzers to understand the dynamic behavior and diurnal variations in $\mathrm{NH}_{3}$ concentrations in animal buildings. Ni and Heber (2008) suggest a response time of less than 2 min to capture temporal $\mathrm{NH}_{3}$ concentration variations. The CRDS shows sufficiently low response times under laboratory (Fig. 3 and Table A2) and field conditions (Fig. 9). These times are also comparable to $<30 \mathrm{~s}$ for responses to $3 \mathrm{ppm}$, as reported by the manufacturer (Picarro, 2017). Furthermore, there are no clear changes in response time without the use of an external particulate matter filter. The tested filters vary by $<10 \mathrm{~s}$ in response time with a tendency towards shorter response times at higher concentrations. The manufacturer reports rise- and fall times of approximately $16 \mathrm{~s}$, which is at minimum twice as much as the present results, Table A2 and Fig. 2. The response to a change from 0 to $1.02 \mathrm{ppm}$ gave response times of 8.1 and $3.2 \mathrm{~s}$ for the rise and fall time, respectively. A change from 0 to 10.02 gave response times of 3.6 and $4.8 \mathrm{~s}$ for the rise and fall time, respectively (Fig. 3). The rise times with external particulate filters connected were 7.3, 3.0, 8.4 and 5.9 s, for SP1, SP2, SP4 and SP5, respectively. Response times are, in general, faster for higher concentration differences (see Fig. 4), which is ascribed to faster surface saturation. The observed concentrations of $\mathrm{NH}_{3}$ released from particulate filters exposed to air from a livestock house for 2 weeks (Fig. 10) suggest that adsorption of $\mathrm{NH}_{3}$ to the filter material, surfaces and walls is negligible. The levels released over 1 min $(<50 \mathrm{ppb})$ should be compared to a filter exposure of ammonia of $>100 \mathrm{ppb}$ (ranging in to low ppm levels) over 2 weeks. These results indicate that the use of external 

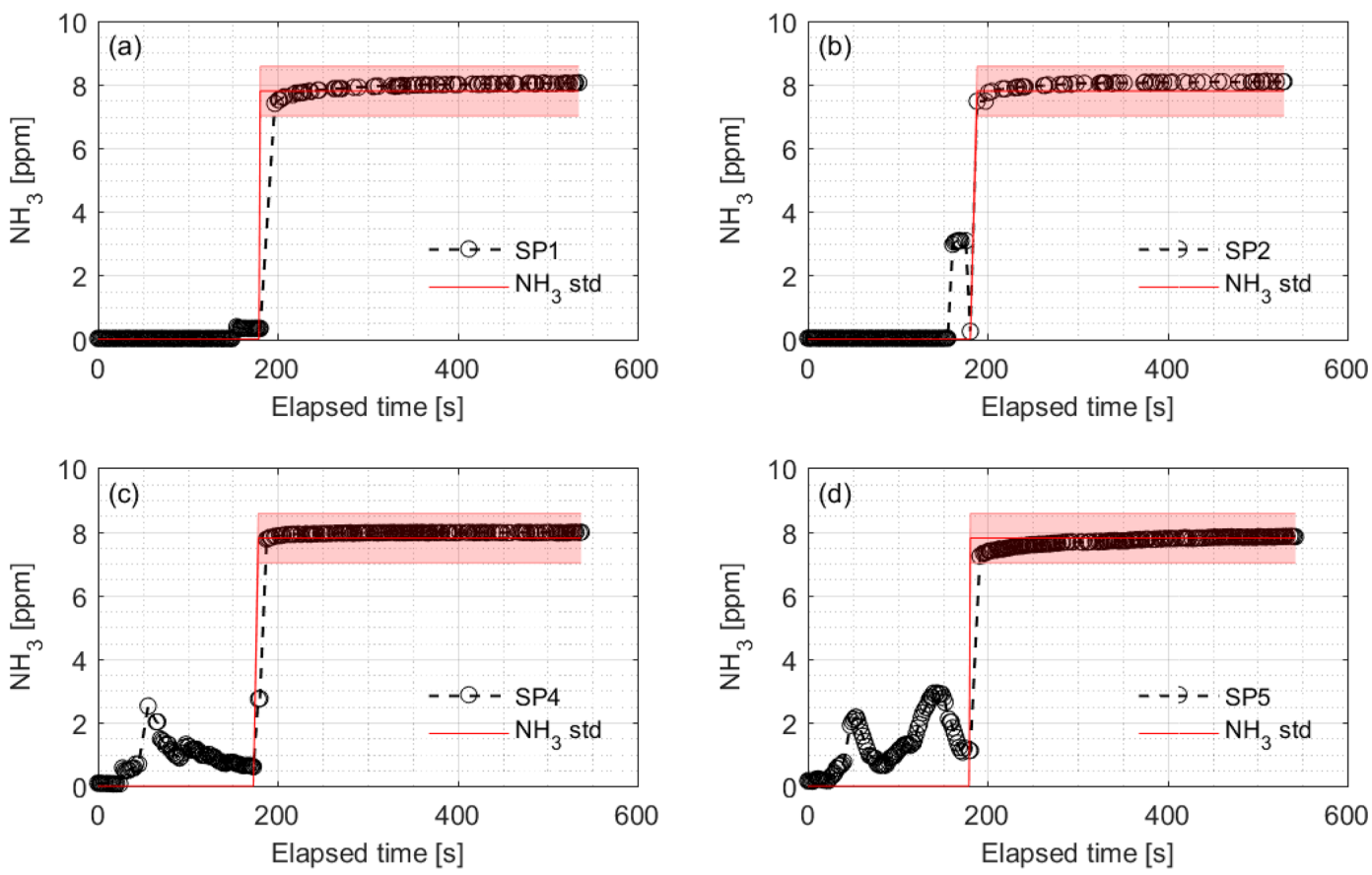

Figure 9. Calibration of the $\mathrm{NH}_{3}$ sampling and measurement system and associated response times of the CRDS during field testing. Introduction of $7.8 \mathrm{ppm} \mathrm{NH}_{3}$ gas was at (a) SP1, (b) SP2, (c) SP4 and (d) SP5 while monitoring the $\mathrm{NH}_{3}$ concentration at the outlet port connected to the analyzer. SP denotes sampling point. The rise times were 7.3, 3.0, 8.4 and 5.9s for SP1, SP2, SP4 and SP5, respectively. The red line and area represent the $\mathrm{NH}_{3}$ standard concentration with uncertainty.

filters gives satisfying response times and no problems with adsorption of $\mathrm{NH}_{3}$ on the filter material.

$\mathrm{CO}_{2}$ and $\mathrm{CH}_{4}$ are present in the atmosphere in relatively high concentrations compared to other trace gasses, and animals produce $\mathrm{CO}_{2}$ and $\mathrm{CH}_{4}$, thus elevated concentrations are normal in animal houses. Over a large concentration range, we observed little scatter and no interference of $\mathrm{CO}_{2}$ and $\mathrm{CH}_{4}$ on $\mathrm{NH}_{3}$ measurements, as seen in Fig. 6. The mean concentrations of both compounds are below the LOQ.

For the interference of single VOCs, it was expected that the different dilutions prepared from clean dry air mixed with humid headspace air over a VOC solution gave a correlation between water vapor and VOC concentration. This was also the case for all 10 volatile compounds. Martin et al. (2016) observe an interference from water vapor on $\mathrm{NH}_{3}$ measurements due to spectral line broadening, which the manufacturer corrects for in all models produced after the publication of that work. Our Picarro analyzer from December 2014 does not make this extra correction, and we thus expected a small water dependency for $\mathrm{NH}_{3}$, which is seen in Fig. 5 . Figure 5 shows the humidity effect on the CRDS signal generated from pure deionized water and reveals a small dependency for water vapor, which the improvements suggested by Martin et al. (2016) potentially remove. Nonetheless, our results show up to $4.5 \mathrm{ppb} \mathrm{NH}_{3}$ for a nearly water-saturated air stream with an absolute $\mathrm{H}_{2} \mathrm{O}$ concentration of approximately $1.1 \%$. Thus, in the extreme case of low $\mathrm{NH}_{3}$ concentrations of $100 \mathrm{pbb}$ and very humid air, a water vapor interference of up to $5 \%$ of the $\mathrm{NH}_{3}$ signal may be present, but under normal conditions this is negligible.

The 10 tested compounds are normally present in sub-ppm levels in agricultural environments (Copeland et al., 2012; Yuan et al., 2017). As seen in Fig. 1, acetic acid and methanol have absorption lines in the wavelength area used for the Picarro CRDS measurements. A concentration range that covers a large dynamic area and exceeds the normal maximum concentration in livestock buildings was used to obtain the potential maximum interference, and we only observed very small water-induced interferences. Figure 7 shows the contribution from the single VOCs that were either corrected for water or uncorrected, and, as can be seen, the interferences are insignificant in general. Overall, the difference between high and low concentration for a single VOC was approximately 1-2 ppb $\mathrm{NH}_{3}$ (Fig. 7), except for acetic acid with a difference of nearly $4 \mathrm{ppb}$. It should be noted that the water to VOC relation differs for the different compounds. With water correction applied, only 1-propanol and acetic acid have increasing tendencies, where $\mathrm{NH}_{3}$ concentration increases about $0.8 \mathrm{ppb}$ for an increase of $7.5 \mathrm{ppm}$ of 1-propanol and $2.9 \mathrm{ppb}$ for an increase of nearly $1.8 \mathrm{ppm}$ of acetic acid. Acetic acid, 2-propanol and propionic acids were the only compounds with absolute humidity above $1 \%$ as we used higher flow rates over the headspace to obtain the targeted concentrations. The very moist sample of acetic acid had a 


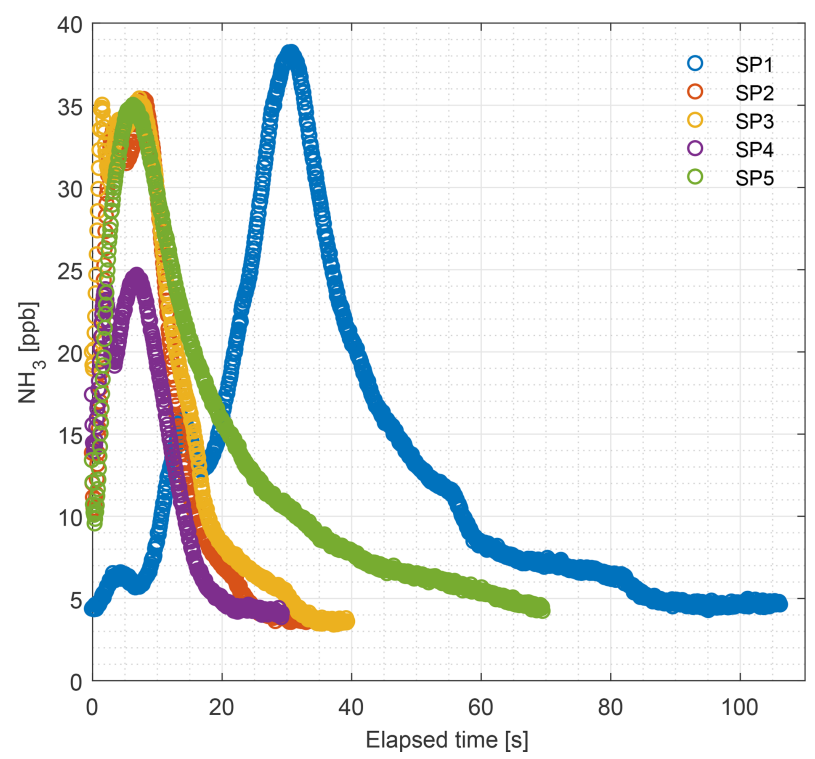

Figure 10. Levels of $\mathrm{NH}_{3}$ concentration in the 2-week-old external particulate filters (PTFE, $0.20 \mu \mathrm{m}$ pore size) measured by the CRDS in the laboratory. Filters collected from the field were installed before each sampling port. SP denotes sampling point.

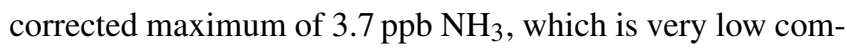
pared to, for example, concentrations in animal buildings, which typically range from $<1$ to $20 \mathrm{ppm}$ but can, in extreme cases, reach up to $50 \mathrm{ppm}$ (Heber et al., 2006; Koerkamp et al., 1998). Thus, errors of a few ppb, introduced by humidity effects, would have a small impact on the results. For the given setup, the interferences from water vapor were in the same order of magnitude as the LOQ of $1.15 \mathrm{ppb}$. For more than half of the VOCs, the $\mathrm{NH}_{3}$ concentration falls below the LOQ for all or most measurement. This demonstrates a very low interference from the investigated VOCs.
The results of this study clearly demonstrate the advantage of CRDS with only few and small interferences, whereas the performance of the photoacoustic analyzers under similar circumstances studied by Liu et al. (2019) showed much more interference from non- $\mathrm{NH}_{3}$ species.

Our tests of the Picarro CRDS showed great linearity during both laboratory and fieldwork. The response times with respect to concentration changes were sufficiently low to measure temporal variations in $\mathrm{NH}_{3}$ concentrations in livestock emissions. Examinations of external particulate filters lead to no clear recommendations for filter material, but all filters gave acceptable response times and only small amounts of $\mathrm{NH}_{3}$ adsorption compared to background levels. Potential interferences were tested for 10 VOCs in known concentrations and the compounds gave negligible interference on CRDS $\mathrm{NH}_{3}$ measurements.

Code and data availability. The data in the study are available upon request to the corresponding author (af@eng.au.dk). 


\section{Appendix A}

Table A1. Measured concentrations of $\mathrm{NH}_{3}, \mathrm{CO}_{2}$ and $\mathrm{CH}_{4}$ in laboratory zero air (CV denotes coefficient of variation).

\begin{tabular}{llrrr}
\hline Gas & Concentration & Mean & $\mathrm{CV}(\%)$ & $\begin{array}{r}\text { Measurement } \\
\text { duration (h) }\end{array}$ \\
\hline $\mathrm{NH}_{3}$ & ppb & 1 & 43 & 19 \\
$\mathrm{CO}_{2}$ & ppm & 480 & 5 & 19 \\
$\mathrm{CH}_{4}$ & ppm & 2.4 & 10 & 19 \\
\hline
\end{tabular}

Table A2. The rise ( $1 / e$ response time) and fall ( $1 / e$ response time) times (s) of the CRDS analyzer for measurements of NH3 concentrations $(0.203$ and $10.01 \mathrm{ppm})$ with or without external inlet particulate filters during laboratory testing. For filters detail see Table 1.

\begin{tabular}{lrrrr}
\hline Filter code & \multicolumn{2}{c}{$0.203 \mathrm{ppm} \mathrm{NH}_{3}$} & \multicolumn{2}{c}{$10.01 \mathrm{ppm} \mathrm{NH}_{3}$} \\
\cline { 2 - 5 } & Rise (s) & Fall (s) & Rise (s) & Fall (s) \\
\hline No filter & 7.3 & 4.7 & 3.3 & 4.9 \\
PTFE 0.2 & 4.8 & 7.1 & 2.0 & 2.7 \\
PTFE 0.5 & 8.0 & 5.3 & 6.0 & 1.5 \\
PTFE 1.0 & 6.9 & 4.9 & 1.8 & 5.3 \\
PTFE 3.0 & 6.3 & 4.5 & 2.1 & 1.4 \\
PTFE 5.0 & 5.3 & 9.5 & 1.2 & 3.2 \\
GA 55 & 12.4 & 8.5 & 1.8 & 2.3 \\
GB 140 & 12.7 & 7.0 & 3.3 & 7.0 \\
GA 200 & 9.3 & 5.6 & 3.3 & 3.0 \\
QR 100 & 8.0 & 5.5 & 5.9 & 5.7 \\
Min & 4.8 & 4.5 & 1.2 & 1.4 \\
Max & 12.7 & 9.5 & 6.0 & 7.0 \\
Mean & 8.1 & 6.3 & 3.1 & 3.7 \\
\hline
\end{tabular}

Figure A1. Schematic of the sampling point inside the cattle building. SP1 and SP5 were placed outside for background measurement at $2.5 \mathrm{~m}$ height. SP2 and SP4 were on the walls at $2.5 \mathrm{~m}$ height. SP3 was placed below the ridge at $9 \mathrm{~m}$ height. The lines were approximately $5,15,35,45$ and $50 \mathrm{~m}$ for SP1, SP2, SP3, SP4 and SP5, respectively. 


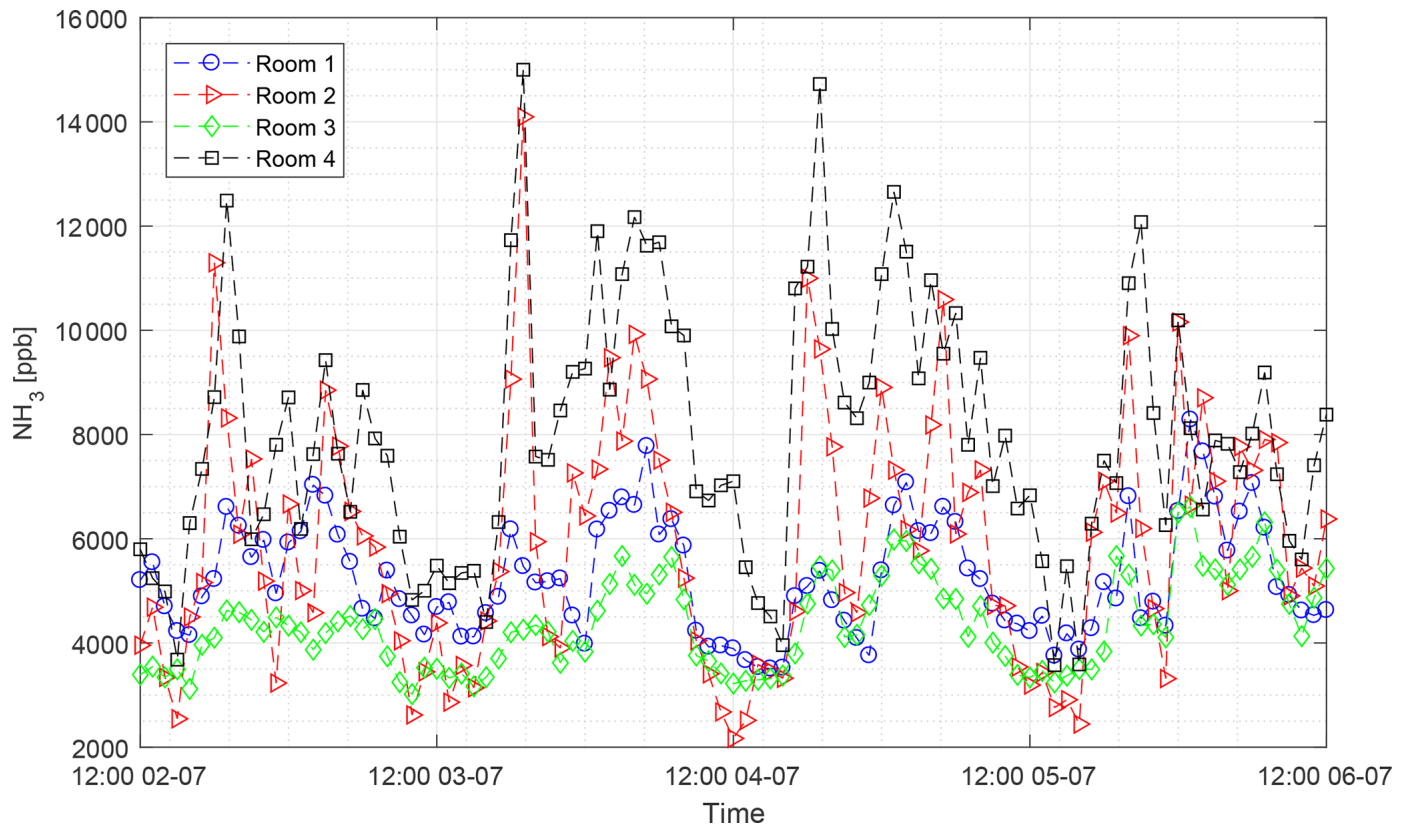

Figure A2. Hourly mean concentrations of $\mathrm{NH}_{3}$ from four different rooms with finisher pigs.

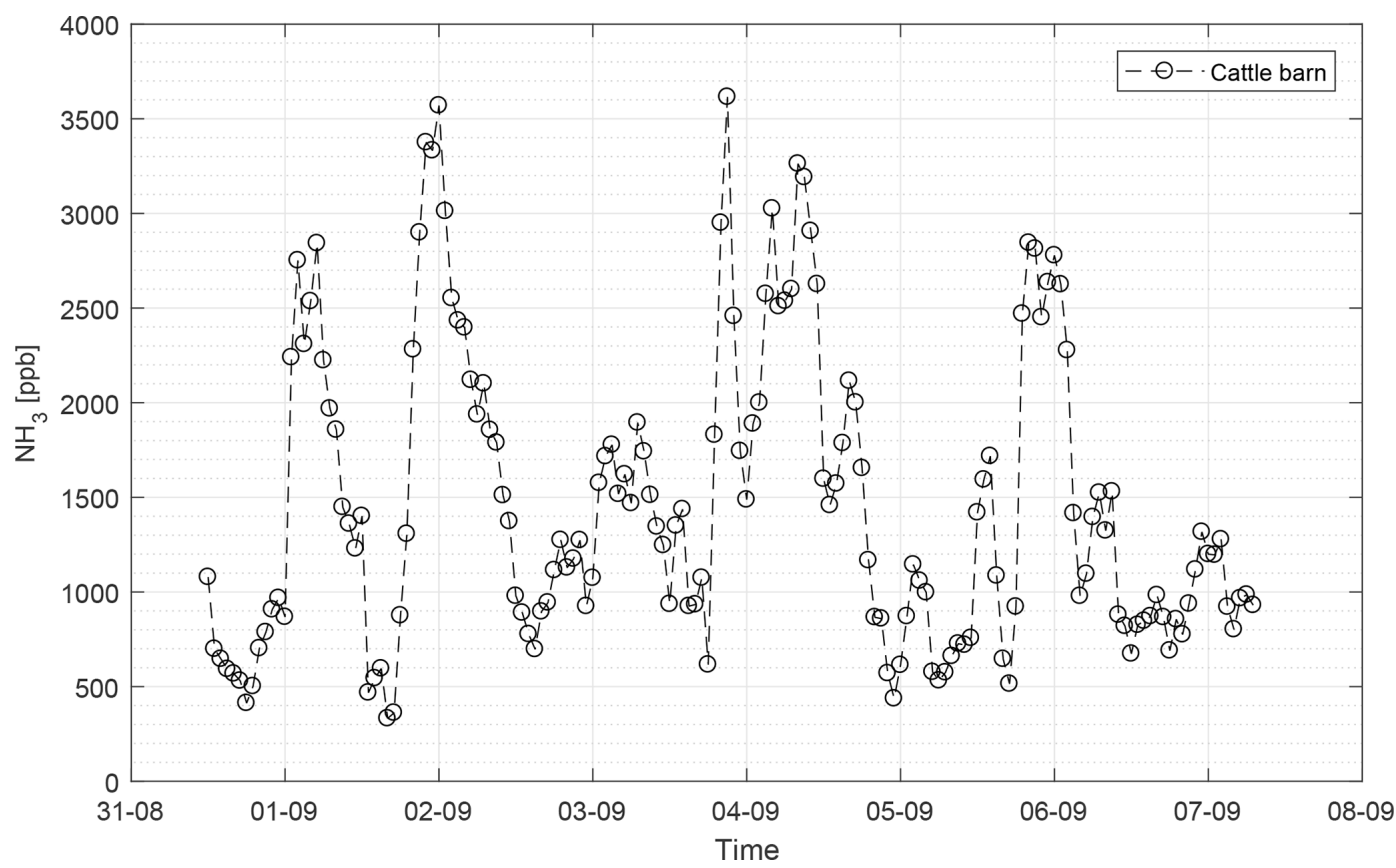

Figure A3. Hourly mean concentrations of $\mathrm{NH}_{3}$ from a dairy cattle barn, unpublished data. 
Author contributions. JK and AC performed the experiments, analysis and drafted the initial manuscript. The work was conceptualized and validated by AF, AC and JK with input from APA on the methodology. All authors have contributed and edited the paper during the review.

Competing interests. The authors declare that they have no conflict of interest.

Acknowledgements. The authors thank laboratory technician Heidi Grønbæk Christiansen and technician Peter Storegård Nielsen for their valuable help during the experimental part of the study. The authors thank the Danish Milk Levy Foundation for funding this research.

Financial support. This research has been supported by the Danish Milk Levy Foundation.

Review statement. This paper was edited by Folkert Boersma and reviewed by two anonymous referees.

\section{References}

Aneja, V. P., Roelle, P. A., Murray, G. C., Southerland, J., Erisman, J. W., Fowler, D., Asman, W. A. H., and Patni, N.: Atmospheric nitrogen compounds II: emissions, transport, transformation, deposition and assessment, Atmos. Environ., 35, $1903-$ 1911, https://doi.org/10.1016/S1352-2310(00)00543-4, 2001.

Baek, B. H., Aneja, V. P., and Tong, Q.: Chemical coupling between ammonia, acid gases, and fine particles, Environ. Pollut., 129, 89-98, https://doi.org/10.1016/j.envpol.2003.09.022, 2004.

Bobrutzki, K. von, Braban, C. F., Famulari, D., Jones, S. K., Blackall, T., Smith, T. E. L., Blom, M., Coe, H., Gallagher, M., Ghalaieny, M., McGillen, M. R., Percival, C. J., Whitehead, J. D., Ellis, R., Murphy, J., Mohacsi, A., Pogany, A., Junninen, H., Rantanen, S., Sutton, M. A., and Nemitz, E.: Field inter-comparison of eleven atmospheric ammonia measurement techniques, Atmos. Meas. Tech., 3, 91-112, https://doi.org/10.5194/amt-3-91-2010, 2010.

Brown, P., Watts, P., Märk, T. D., and Mayhew, C. A.: Proton transfer reaction mass spectrometry investigations on the effects of reduced electric field and reagent ion internal energy on product ion branching ratios for a series of saturated alcohols, Int. J. Mass Spectrom., 294, 103-111, https://doi.org/10.1016/j.ijms.2010.05.028, 2010.

Copeland, N., Cape, J. N., and Heal, M. R.: Volatile organic compound emissions from Miscanthus and short rotation coppice willow bioenergy crops, Atmos. Environ., 60, 327-335, https://doi.org/10.1016/j.atmosenv.2012.06.065, 2012.

Feilberg, A., Liu, D., Adamsen, A. P. S., Hansen, M. J., and Jonassen, K. E. N.: Odorant Emissions from Intensive Pig Production Measured by Online Proton-Transfer-Reaction
Mass Spectrometry, Environ. Sci. Technol., 44, 5894-5900, https://doi.org/10.1021/es100483s, 2010.

Gordon, I. E., Rothman, L. S., Hill, C., Kochanov, R. V, Tan, Y., Bernath, P. F., Birk, M., Boudon, V., Campargue, A., Chance, K. V, Drouin, B. J., Flaud, J., Gamache, R. R., Hodges, J. T., Jacquemart, D., Perevalov, V. I., Perrin, A., Shine, K. P., Smith, M. H., Tennyson, J., Toon, G. C., Tran, H., Tyuterev, V. G., Barbe, A., Császár, A. G., Devi, V. M., Furtenbacher, T., Harrison, J. J., Hartmann, J., Jolly, A., Johnson, T. J., Karman, T., Kleiner, I., Kyuberis, A. A., Loos, J., Lyulin, O. M., Massie, S. T., Mikhailenko, S. N., Moazzen-ahmadi, N., Müller, H. S. P., Naumenko, O. V, Nikitin, A. V, Polyansky, O. L., Auwera, J. Vander, Wagner, G., Wilzewski, J., Wcis, P., Yu, S., and Zak, E. J.: Journal of Quantitative Spectroscopy \& Radiative Transfer The HITRAN2016 molecular spectroscopic database, J. Quant. Spectrosc. Ra., 203, 3-69, https://doi.org/10.1016/j.jqsrt.2017.06.038, 2017.

Hafner, S. D., Howard, C., Muck, R. E., Franco, R. B., Montes, F., Green, P. G., Mitloehner, F., Trabue, S. L., and Rotz, C. A.: Emission of volatile organic compounds from silage: Compounds, sources, and implications, Atmos. Environ., 77, 827839, https://doi.org/10.1016/j.atmosenv.2013.04.076, 2013.

Hansen, M. J., Liu, D., Guldberg, L. B., and Feilberg, A.: Application of proton-transfer-reaction mass spectrometry to the assessment of odorant removal in a biological air cleaner for pig production, J. Agr. Food Chem., 60, 2599-2606, https://doi.org/10.1021/jf300182c, 2012.

Hassouna, M., Robin, P., Charpiot, A., Edouard, N., and Méda, B.: Infrared photoacoustic spectroscopy in animal houses: Effect of non-compensated interferences on ammonia, nitrous oxide and methane air concentrations, Biosyst. Eng., 114, 318-326, https://doi.org/10.1016/j.biosystemseng.2012.12.011, 2013.

Heber, A. J., Ni, J.-Q., Lim, T. T., Tao, P.-C., Schmidt, A. M., Koziel, J. A., Beasley, D. B., Hoff, S. J., Nicolai, R. E., Jacobson, L. D., and Zhang, Y.: Quality Assured Measurements of Animal Building Emissions: Gas Concentrations, J. Air Waste Manage. Assoc., 56, 1472-1483, https://doi.org/10.1080/10473289.2006.10465680, 2006.

Huszár, H., Pogány, A., Bozóki, Z., Mohácsi, Á., Horváth, L., and Szabó, G.: Ammonia monitoring atppb level using photoacoustic spectroscopy for environmental application, Sensors Actuat. B-Chem., 134, 1027-1033, https://doi.org/10.1016/j.snb.2008.05.013, 2008.

Koerkamp, P. W. G. G., Metz, J. H. M., Uenk, G. H., Phillips, V. R., Holden, M. R., Sneath, R. W., Short, J. L., White, R. P. P., Hartung, J., Seedorf, J., Schröder, M., Linkert, K. H., Pedersen, S., Takai, H., Johnsen, J. O., and Wathes, C. M.: Concentrations and Emissions of Ammonia in Livestock Buildings in Northern Europe, J. Agr. Eng. Res., 70, 79-95, https://doi.org/10.1006/jaer.1998.0275, 1998.

Liu, D., Rong, L., Kamp, J., Kong, X., Adamsen, A. P., Chowdhury, A., and Feilberg, A.: Photoacoustic measurement may significantly overestimate $\mathrm{NH}_{3}$ emissions from cattle houses due to VOC interferences, Atmos. Meas. Tech. Discuss., https://doi.org/10.5194/amt-2018-412, in review, 2019.

Maasikmets, M., Teinemaa, E., Kaasik, A., and Kimmel, V.: Measurement and analysis of ammonia, hydrogen sulphide and odour emissions from the cattle farming in Estonia, Biosyst. Eng., 139, 
48-59, https://doi.org/10.1016/j.biosystemseng.2015.08.002, 2015.

Martin, N. A., Ferracci, V., Cassidy, N., and Hoffnagle, J. A.: The application of a cavity ring-down spectrometer to measurements of ambient ammonia using traceable primary standard gas mixtures, Appl. Phys. B, 122, 1-11, https://doi.org/10.1007/s00340016-6486-9, 2016.

Ngwabie, N. M., Schade, G. W., Custer, T. G., Linke, S., and Hinz, T.: Abundances and Flux Estimates of Volatile Organic Compounds from a Dairy Cowshed in Germany, J. Environ. Qual., 37, 565-573, https://doi.org/10.2134/jeq2006.0417, 2008.

Ngwabie, N. M., Jeppsson, K. H., Nimmermark, S., Swensson, C., and Gustafsson, G.: Multi-location measurements of greenhouse gases and emission rates of methane and ammonia from a naturally-ventilated barn for dairy cows, Biosyst. Eng., 103, 6877, https://doi.org/10.1016/j.biosystemseng.2009.02.004, 2009.

Ni, J.-Q. and Heber, A. J.: Sampling and Measurement of Ammonia at Animal Facilities, Adv. Agron., 98, 201-269, 2008.

Nielsen, O. K., Plejdrup, M. S., Winther, M., Mikkelsen, M. H., Nielsen, M., Gyldenkærne, S., Fauser, P., Albrektsen, R., Hjelgaard, K. H., Bruun, H. G., and Thomsen, M.: Annual Danish Informative Inventory Report to UNECE, Emission inventories from the base year of the protocols to year 2015, Aarhus University, DCE - Danish Centre for Environment and Energy, 2017.

Picarro, I.: NH3 Analyzer for Ambient Air Datasheet, archived by WebCite ${ }^{\circledR}$, available at: http://www.webcitation.org/70JfzdB0u (last access: 20 June 2018), 2017.

Poissant, L., Pilote, M., Beauvais, C., Constant, P., and Zhang, H. H.: A year of continuous measurements of three atmospheric mercury species (GEM, RGM and $\mathrm{Hg} \mathrm{p}$ ) in southern Québec, Canada, Atmos. Environ., 39, 1275-1287, https://doi.org/10.1016/j.atmosenv.2004.11.007, 2005.

Rom, H. B. and Zhang, G. Q.: Time delay for aerial Ammonia concentration measurements in livestock buildings, Sensors, 10, 4634-4642, https://doi.org/10.3390/s100504634, 2010.

Rong, L., Liu, D., Pedersen, E. F., and Zhang, G.: Effect of climate parameters on air exchange rate and ammonia and methane emissions from a hybrid ventilated dairy cow building, Energy Build., 82, 632-643, https://doi.org/10.1016/j.enbuild.2014.07.089, 2014.

Rosenstock, T. S., Diaz-Pines, E., Zuazo, P., Jordan, G., Predotova, M., Mutuo, P., Abwanda, S., Thiong'o, M., Buerkert, A., Rufino, M. C., Kiese, R., Neufeldt, H., and ButterbachBahl, K.: Accuracy and precision of photoacoustic spectroscopy not guaranteed, Glob. Change Biol., 19, 3565-3567, https://doi.org/10.1111/gcb.12332, 2013.

Saha, C. K., Zhang, G., Kai, P., and Bjerg, B.: Effects of a partial pit ventilation system on indoor air quality and ammonia emission from a fattening pig room, Biosyst. Eng., 105, 279-287, https://doi.org/10.1016/j.biosystemseng.2009.11.006, 2010.
Shah, S. B., Grabow, G. L., and Westerman, P. W.: Ammonia Adsorption in Five Types of Flexible Tubing Materials, Am. Soc. Agr. Biol. Eng., 22, 919-923, 2006.

Shaw, S. L., Mitloehner, F. M., Jackson, W., Depeters, E. J., Fadel, J. G., Robinson, P. H., Holzinger, R., and Goldstein, A. H.: Volatile organic compound emissions from dairy cows and their waste as measured by proton-transfer-reaction mass spectrometry, Environ. Sci. Technol., 41, 1310-1316, https://doi.org/10.1021/es061475e, 2007.

Sheppard, L. J., Leith, I. D., Mizunuma, T., Neil Cape, J., Crossley, A., Leeson, S., Sutton, M. A., van Dijk, N., and Fowler, D.: Dry deposition of ammonia gas drives species change faster than wet deposition of ammonium ions: evidence from a longterm field manipulation, Glob. Change Biol., 17, 3589-3607, https://doi.org/10.1111/j.1365-2486.2011.02478.x, 2011.

Sintermann, J., Ammann, C., Kuhn, U., Spirig, C., Hirschberger, R., Gärtner, A., and Neftel, A.: Determination of field scale ammonia emissions for common slurry spreading practice with two independent methods, Atmos. Meas. Tech., 4, 1821-1840, https://doi.org/10.5194/amt-4-1821-2011, 2011.

Vaittinen, O., Metsälä, M., Persijn, S., Vainio, M., and Halonen, L.: Adsorption of ammonia on treated stainless steel and polymer surfaces, Appl. Phys. B, 115, 185-196, https://doi.org/10.1007/s00340-013-5590-3, 2014.

Wu, W., Zhang, G., and Kai, P.: Ammonia and methane emissions from two naturally ventilated dairy cattle buildings and the influence of climatic factors on ammonia emissions, Atmos. Environ., 61, 232-243, https://doi.org/10.1016/j.atmosenv.2012.07.050, 2012.

Yuan, B., Coggon, M. M., Koss, A. R., Warneke, C., Eilerman, S., Peischl, J., Aikin, K. C., Ryerson, T. B., and De Gouw, J. A.: Emissions of volatile organic compounds (VOCs) from concentrated animal feeding operations (CAFOs): Chemical compositions and separation of sources, Atmos. Chem. Phys., 17, 49454956, https://doi.org/10.5194/acp-17-4945-2017, 2017.

Zhang, G., Strøm, J. S., Li, B., Rom, H. B., Morsing, S., Dahl, P., and Wang, C.: Emission of ammonia and other contaminant gases from naturally ventilated dairy cattle buildings, Biosyst. Eng., 92, 355-364, https://doi.org/10.1016/j.biosystemseng.2005.08.002, 2005.

Zhao, Y., Pan, Y., Rutherford, J., and Mitloehner, F. M.: Estimation of the interference in Multi-Gas measurements using infrared photoacoustic analyzers, Atmosphere, 3, 246-265, https://doi.org/10.3390/atmos3020246, 2012.

Zhu, X., Burger, M., Doane, T. A., and Horwath, W. R.: Ammonia oxidation pathways and nitrifier denitrification are significant sources of $\mathrm{N}_{2} \mathrm{O}$ and $\mathrm{NO}$ under low oxygen availability, P. Natl. Acad. Sci. USA, 110, 6328-6333, 2013.

Zong, C., Feng, Y., Zhang, G., and Hansen, M. J.: Effects of different air inlets on indoor air quality and ammonia emission from two experimental fattening pig rooms with partial pit ventilation system - Summer condition, Biosyst. Eng., 122, 163-173, https://doi.org/10.1016/j.biosystemseng.2014.04.005, 2014. 